\section{Transgressões ao estigma de mulher negra e projeções de um self ressignificado}

Transgressions to the stigma of black women and projections of a resignified self

Allane de Souza PEDROTTI (PUC-RJ) allane_pedrotti@yahoo.com.br

Recebido em: 05 de maio de 2018. Aceito em: 28 de abr. de 2019.
PEDROTTI, Allane de Souza.

Transgressões ao estigma de

mulher negra e projeções de um

self ressignificado. Entrepalavras,

Fortaleza, v. 9, n. 2, p. 61-78, maio-

ago/2019

Resumo: Com base no conceito de Estigma por Goffman (1988), este artigo se debruça sobre a narrativa gerada em entrevista com uma mulher negra que remonta seu trajeto de vida, distanciando-se do estigma imposto pela sociedade a uma mulher negra. Objetiva localizar e entender as marcas de ruptura ao estigma e os momentos de proteção de face e de projeção de self frente à transgressão a este destino normatizado. Para tal, a entrevista foi objeto de análise discursiva interacional, através de aparatos categóricos oferecidos pela sociolinguística interacional, com recorte da análise narrativa. Traz como resultado o esforço pela desconstrução dos signos estigmatizantes pela participante, que ressignifica as marcas e os estigmas sociais racistas sofridos por uma mulher negra.

Palavras-chave:Estigma. Sociolinguística interacional. Projeção de self. 
V. $9(2)$

61-78 maio-ago 2019

Abstract: Based on the concept of Stigma by Goffman (1988), this article analyses the narrative from an interview with a black woman who retraces her life during her narrative, distancing herself from the stigma imposed by society on a black woman. It aims to locate and understand the stigma rupture and the face protections and self projection moments through the transgression of her established destiny. For this purpose, the interview was subjected to interactional discourse analysis, through categorical devices offered by interactional sociolinguistics, narrowing the narrative analysis. The result is the effort to deconstruct the participant's stigmatizing signs, which resignifies the racist marks and social stigmas suffered by a black woman.

Keywords: Stigma. Interactional sociolinguistics. Self-presentation.

\section{Introdução}

No presente artigo analiso a narrativa de uma mulher negra que (re)constrói a identidade ao contar sua história de vida. Para tal, articulo o conceito de estigma, de Goffman (1988), e o constante trabalho de face que marca o que chamo de transgressão ao comportamento e ao destino normatizados socialmente e esperados para uma mulher negra, qual seja, o de empregada doméstica ou profissões similares, na sociedade historicamente opressora em que vivemos. Em um contexto macrossocial no qual as situações de racismo sofridas moldam os comportamentos de pessoas negras, diante de suas vivências e experiências de vida, considerarei aqui a mulher negra como a estigmatizada diante das expectativas de sociedade esperadas e o esforço em situações sociais relatadas para se projetar de fora do estigma a ela imputado.

A relação assimétrica entre o negro e o branco, construída historicamente após as colonizações vividas no Brasil, modela a formação social brasileira sobre as representações das relações entre as etnias. Antes e após o regime escravocrata, os sistemas de produção econômica, social e político vividos ao longo da história brasileira explicam o estabelecimento da hierarquização dos papéis de senhor e de escravo (FREYRE, 2006). A extensão desses papéis figura nas relações atuais entre o negro e o branco, mesmo após significantes modificações ideológicas que vêm se remodelando através das lutas dos coletivos e da preocupação pela aceitação da diversidade. Apesar do avanço nas lutas, há ainda a prevalência da separação dos papeis do negro e do branco em hierarquização, não só nas relações trabalhistas como nas pessoais, permeadas por ideologias racistas.

A questão principal que abordo neste artigo é como uma mulher negra, estigmatizada pela sociedade, (re)modela a projeção de um self na construção narrativa de suas histórias de vida, protegendo a sua face 
diante da interação proposta. Deste modo, objetivo entender de que forma a participante, mulher negra, se constrói para se apresentar no encontro que Goffman (1988) define como misto, à luz das representações relacionais entre pessoas brancas e negras construídas ao longo do processo histórico brasileiro. Objetivo, também, analisar quais recursos léxico-gramaticais ela utiliza como esforço para a transgressão ao destino esperado a uma mulher negra e quais mecanismos de proteção à face aparecem ao longo de suas narrativas.

Para tal, realizo a contextualização sobre a participante e sobre o campo de pesquisa no qual os dados foram gerados, indicando o viés metodológico utilizado. Em seguida, dou corpo teórico para ulterior análise tecendo um resumido aparato conceitual sobre o conceito de estigma desenvolvido por Goffman (1988), realizando a articulação com o trabalho de self e manipulação de identidade estigmatizada. Articulo, então, a abordagem de narrativa de história de vida com os processos de construção identitária e sua relação com o rótulo entregue ao estigmatizado. Por fim, parto para a análise dos dados gerados, sob a lente dos conceitos estudados.

\section{Contextualização e caminhos metodológicos}

O corpus desta pesquisa foi gerado através de uma interação proposta pela pesquisadora com uma funcionária, protegida nas transcrições em análise sob o pseudônimo de Lia, assistente social e mulher negra que é servidora em um Centro de Educação Tecnológica Federal, onde atuou por cerca de vinte anos com atendimento de orientação educacional a alunos de ensino médio. A interação foi gravada em forma de áudio e girou em torno de perguntas que remontaram a sua história de vida, suas histórias de racismo e sua opinião acerca da política de cotas e coletivos negros.

O Centro Federal em referência atende à política de cotas do governo federal, cuja separação de cinquenta por cento vagas se dá pela origem escolar de escola pública, renda familiar e autodeclaração de negro, pardo ou índio, em consonância à lei $n^{0}$ 12.711/2012. Até a data da legislação, a escola recebia alunos de classe média e oriundos de escolas particulares ou cursos preparatórios. Com este cenário surgido da demanda legislativa, a instituição passou a receber em seu corpo discente uma mistura equilibrada entre alunos de renda média oriundos de trajetória escolar de instituições particulares e alunos de 
V. 9 (2)

61-78 maio-ago 2019 renda baixa, o que aparentemente tem causado estranheza ao corpo docente e servidores administrativos em educação, tendo em vista o clima tradicionalista que domina a instituição.

Com uma base etnográfica, este trabalho cunha a interação face a face com a participante, frente a já conhecida estrutura de funcionamento da instituição por parte da pesquisadora. Através desta característica de pesquisa, foi possível a busca pelo entendimento das construções identitárias da participante nas redes de significados ali existentes. Do mesmo modo, a análise de narrativa traz o olhar da perspectiva interacionista, que ofereceu suporte como categoria de análise das escolhas léxico-gramaticais e das narrativas que compunham a história de vida da participante para a projeção do self por ela desejado, sob uma perspectiva êmica.

Como abordagem complementar para melhor compreensão da estrutura narrativa e seus sistemas de coerência, busco, na análise de estrutura narrativa de Labov (1972) e na história de vida de Linde (1993), aportes teóricos que sustentam as análises de discurso sob a abordagem central aqui utilizada do conceito de estigma, por Goffman (1988). Tal conceito guiou as costuras realizadas através das narrativas da participante, na interação social proposta, tendo em vista a história de vida dar possibilidades de compreensão do modo como se organiza a vida passada na situação atual (LINDE, 1993, p. 11).

\section{Conceito de estigma por Goffman}

Considero aqui, com base no conceito de estigma traçado por Goffman, o indivíduo estigmatizado como aquele que está ou é inabilitado para a aceitação social. Para dar corpo às definições que aqui abordarei, faz-se necessária uma breve explicação sobre identidade social virtual e identidade social real. Constantemente projetamos sobre o outro expectativas normativas a serem preenchidas considerando os atributos necessários a esta normalidade social, o que chamamos identidade social virtual. Em contraponto e, por vezes, em sentido diametralmente oposto, está a identidade social real, que apresenta as categorias e atributos atuais que ele prova possuir (GOFFMAN, 1988, p. 12).

Neste sentido, o estigma surge onde está presente alguma expectativa socialmente estabelecida, que é quebrada, dando espaço para a tensão entre o atributo e o estereótipo, ou seja, abre-se a diferença 
entre o que projetamos e o real, constituindo-se o estigma através de um atributo, então, depreciativo do sujeito. A posição que ele passa a ocupar na sociedade é a de não aceitação devido à informação social negativa sobre si que ele mesmo transmite ao outro, seja de modo voluntário ou involuntário (BIAR, 2015, p. 117). A condição de entendimento da situação social (GOFFMAN, 2002, p. 14), que a define, afeta a ação social do sujeito e a articulação para melhor construção de si na interação sob a projeção de um self favorável. Goffman (2009) significa o self como resultado de um processo social a partir de padrões estabelecidos pela sociedade e pelos outros sujeitos das interações sociais.

No presente estudo, considero a pessoa negra como estigmatizada, tendo em vista o histórico de racismo intrínseco em nossa sociedade, na qual a cor da pele que destoa da branquitude como normativa social traz às pessoas negras uma série de identificações negativas e expectativas de depreciação de modos de vida e comportamentos. Partindo do estigma que historicamente acompanha a pessoa negra, nos encontros mistos de co-presença, ou seja, quando são reunidos em interação face a face o estigmatizado e o não estigmatizado (GOFFMAN, 1988), os envolvidos enfrentam diretamente as causas e efeitos do estigma, trazendo ao indivíduo estigmatizado uma insegurança sobre o que o indivíduo não estigmatizado identificará nele como atributo negativo e qual o status a ele será atribuído (GOFFMAN, 1988).

Considerando a possibilidade do posicionamento negativo nos encontros mistos, pode haver uma reação defensiva por parte do estigmatizado, apresentando-se, então, de antemão com agressividade na interação face a face (GOFFMAN, 1988). Esta postura traz o efeito de desequilíbrio em todos os participantes do encontro, abrindo espaço para que o estigmatizado esteja pronto para ler significados não intencionais nas ações do outro. Há de se considerar, neste sentido, que:

[...] as identidades se manifestam em co-presença a partir de sinais de várias naturezas que a todo tempo os participantes de interações cotidianas emitem e interpretam. (BIAR, 2015, p. 116).

A partir destes sinais, a situação social é entendida e definida, orientando o modo como o indivíduo deverá agir.

Cabe aqui atenção especial ao que Goffman (1998) chama de desidentificadores que, frente à identidade social virtual, são signos que tendem à quebra da imagem do estigmatizado, direcionando a símbolos positivos que possibilitam o estabelecimento de um novo atributo que 
v. 9 (2)

61-78

maio-ago

2019 põe em dúvida a validade da identidade virtual projetada a ele. Esta quebra o posiciona em um novo status não esperado, que transmite, então, uma nova informação social através destes signos. Goffman (1988, p. 55-56) completa que:

[...] os signos que transmitem a informação social variam em função de serem, ou não, congênitos e, se não o são, em função de, uma vez empregados, tornarem-se, ou não, uma parte permanente. (A cor da pele é congênita; a marca de uma queimadura ou mutilação é permanente mas não congênita; a cabeça raspada de um presidiário não é nem uma coisa nem outra).

Deste modo, a participante negra do presente estudo possui um signo inato que transmite a informação social, que dá a ela, por aqui interpretado, atributos estigmatizantes, conforme historicamente e socialmente estabelecido. Do mesmo modo, ela devolveà sociedade signos desidentificadores, retirando-a do local esperado e posicionando-a em um status "positivo" dentro das normativas estabelecidas socialmente para uma pessoa branca e não para uma pessoa negra, havendo, então, o esforço de proteção de face da participante estigmatizada. O conceito de face é aqui utilizado como o esforço de nos apresentarmos sempre sob uma luz favorável. Goffman (2011 [1967], p. 14) define a face como:

[...] o valor social positivo que uma pessoa efetivamente reivindica para si mesma através da linha que os outros pressupõem que ela assumiu durante um contato particular. Construída, portanto, dialogicamente, face é uma imagem do self delineada "em termos de atributos sociais aprovados.

Tanto para estigmas visíveis quanto para os não-visíveis, a relação de interação em um encontro misto torna-se delicada tendo em vista a identidade social e as diferenças existentes entre os participantes, devido às quais precisam enfrentar os efeitos da interpretação de seus atributos para manter a interação fluida (BIAR, 2015, p. 118). Goffman (1988, p. 65) aborda a possibilidade de haver discrepâncias entre a identidade social virtual e a sociedade social real e que por isso haverá um esforço para a manipulação da situação. Acrescenta que "todo o problema da manipulação do estigma é influenciado pelo fato de conhecermos, ou não, pessoalmente o indivíduo estigmatizado" (GOFFMAN, 1988, p. 65), influência essa que é explicada pela identidade pessoal do indivíduo, que pode desempenhar um papel padronizado na organização social (GOFFMAN, 1988, p. 67). 


\section{Narrativa, história de vida e construção identitária}

De modo extensivo à discussão da seção anterior, a construção de identidade de um indivíduo vem atravessada por construções adjacentes a ele, o que inclui o modo como escolhe se projetar ao outro, dentro de uma unidade social reconhecida por ele. Neste sentido, Linde (1993, p. 3) concorda que "para existir no mundo social o indivíduo necessita projetar uma história de vida coerente e aceitável e, portanto, constantemente revisada de modo a garantir a estabilidade socialmente apropriada". Isso significa que a escolha de repertório de histórias que irá tomar não só constrói o self (GOFFMAN, 1988) que se deseja projetar, mas reconstrói sua própria identidade e que, no momento da elaboração de sua narrativa, encaixam-se nas novas unidades sociais reconhecidas.

Para esta reflexão, então, trabalho com o conceito de identidade construída socialmente através do discurso e das interações (LOPES, 2003). Neste sentido, Nóbrega (2015, p. 254) entende que a identidade é construída e moldada a cada interação discursiva, com a característica de transformação "a cada momento durante a interação e emergentes no contexto discursivo".

Reisseman (2008, p. 8) explica que as narrativas reconstroem as histórias experimentadas no passado e ao mesmo tempo trazem oportunidade de entender ou criar o sentido desse passado através de formas individuais de interpretação. Para Labov (1972), as narrativas possibilitam reviver eventos do passado e a recriação de si temporalmente organizada (RABELO, 2011) possibilita a reinterpretação das próprias histórias de vida narradas, aprofundando as reflexões e influenciando a construção da própria identidade. Portanto, a narrativa é tomada neste estudo como prática discursiva, abrindo espaço para a "compreensão da relação entre discurso, identidade e sociedade" (FABRÍCIO; BASTOS, 2009, p. 41-42).

Sendo assim, considerando uma função além da contação de histórias de construção identitária, a narrativa de história de vida possibilita a construção de identidade social, expondo idiossincrasias de sua cultura. Em relação a esta ideia, encontro no processo de criação de coerência de Linde (1993) consonância com a concepção de cumprimento com a obrigação social do indivíduo, de forma que se construam, então, como "membros competentes da sua cultura" (LINDE, 1993, p. 16). 
v. 9 (2)

61-78 maio-ago 2019

Neste sentido, os sistemas de coerência constituem-se não só em demanda social como individual, visto que a história de vida como unidade social mantém relação com a história de vida privada. Esta ótica conduz à ideia de que o que se produz para se externalizar precisa ser coerente com a adequação social estabelecida (LINDE, 1993). Na unidade social, os indivíduos utilizam a forma narrativa como forma de argumentação (REISSEMAN, 2008, p. 8) e ali negociam com o outro, com histórias de vida que expressam o self, quem são e de que modo se construíram até este ponto, constituindo-se, então, como importante instrumento através do qual se comunica ao outro este self (LINDE, 1993, p. 3). Em consonância com esta reflexão, Biar (2015, p. 120) explica que:

[...] em narrativas de história de vida são negociadas explicações para o extraordinário das quebras de expectativas, ancoradas em sistemas de coerência que tornam essas experiências compreensíveis ou aceitáveis dentro de um quadro de referência maior.

Por fim, as histórias de vida pressupõem o que pode ser tomado como esperado, fazendo surgir, do estabelecimento da coerência, normas e crenças comuns ou especiais que se referem às construções sociais (LINDE, 1993, p. 3).

\section{Uma vida não segregada: apresentação da identidade social transgressora ao estigma}

Nesta seção de análise inicio o estudo das narrativas da participante de modo a responder à questão principal da pesquisa e atender aos objetivos delimitados na seção de introdução deste artigo. Analiso as projeções do self e proteção à face que surgem nas narrativas que Lia remonta através de seus relatos de não segregação.

No Excerto 1, Lia remonta sua história de vida através da narrativa em que conta como foi criada na casa onde sua mãe trabalhava como doméstica. Lia expõe o tratamento que recebia da patroa da mãe, a quem chamava de madrinha, que considerava Lia e sua irmã como filhas. Para dar sustentação a sua história, ela traz exemplos narrativos do que sua madrinha fazia com elas, explicitando que a tratava como uma filha biológica. O uso da contínua repetição da palavra "filha" é percebido aqui como uma forma de convencer quem escuta a sua história de que o tratamento que ela recebia não era a de empregada doméstica, demonstrando conhecimento do estereótipo social que marca mulheres 
negras. Do mesmo modo, a utilização na forma diminutiva "filhinha" reforça o empenho em colocar a madrinha em um papel de "salvadora" e boa.

Excerto 1 - "a gente frequentava os lugares bons com ela"

\begin{tabular}{|c|c|c|}
\hline Pesq & 1 & e você fez o normal $\downarrow$ né? XXXX \\
\hline Lia & $\begin{array}{l}2 \\
3 \\
4 \\
5 \\
6 \\
7 \\
8 \\
9 \\
10 \\
11 \\
12 \\
13 \\
14 \\
15 \\
16 \\
17 \\
18 \\
19 \\
20 \\
21 \\
22 \\
23 \\
24\end{array}$ & 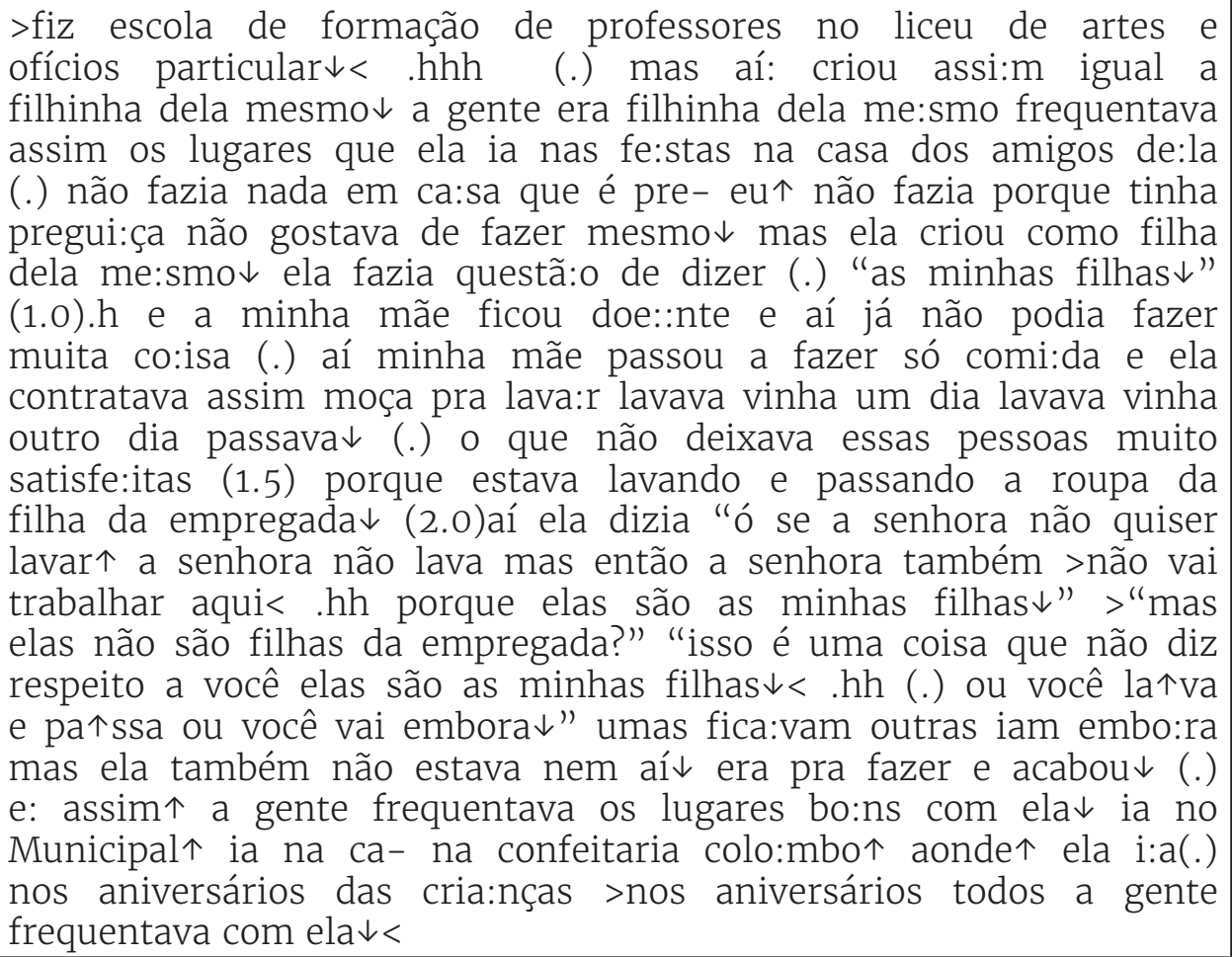 \\
\hline
\end{tabular}

Ao se descrever como mulher que na infância foi tratada como filha legítima de sua madrinha, Lia procura retomar em sua fala comportamentos que ela assumiu como identidade social que também a retiram da marca de empregada doméstica, quando, nas linhas 6, 7 e 8 ("não fazia nada em ca:sa que é pre- eu个 não fazia porque tinha pregui:ça não gostava de fazer mesmo $\downarrow$ mas ela criou como filha dela me:smo $\downarrow$ "), ratificam a possibilidade de escolha que possuía, ao poder ser "preguiçosa", tendo em vista o relato da não obrigatoriedade do trabalho doméstico. Considero aqui como um esforço de projeção de self de modo a colocá-la em local oposto ao estereótipo estabelecido para uma mulher negra e filha de empregada doméstica, cujo destino espera-se que seja o mesmo para todas.

Frente à histórica estrutura social de depreciação dos negros, a cor da pele constitui-se característica de estigma, trazendo consigo o efeito de descrédito, consolidando a discrepância entre a identidade social virtual e a identidade social real da participante. Assim, através de sua reconstrução 
V. $9(2)$

61-78 maio-ago 2019

identitária com sua narrativa de vida, ela reclassifica sua situação, reposicionando-se em uma categoria diferente, que traz a possibilidade de alteração positiva sobre sua avaliação social (GOFFMAN, 1988, p. 12-13).

Nas linhas 9, 10 e 11 ("e a minha mãe ficou doe::nte e aí já não podia fazer muita co:isa (.) aí minha mãe passou a fazer só comi:da e ela contratava assim moça pra lava:r"), Lia inicia a retirada também da sua mãe do papel de empregada doméstica, colocando-a em posição também diferenciada, o que auxilia a sustentar a justificativa que procura ao convencer que sua madrinha possuía um sentimento diferente por elas, projetando, também, a patroa em um papel benevolente. Vale atentar, também, para o fato da queda visível de entonação quando fala a palavra "filha(s)", nas linhas 7, 8, 16 e 18, o que marca a hesitação em sua prosódia.

Para dar corpo e veracidade ao que narra, expondo e definindo a sua identidade social, Lia retrata os locais para onde sua madrinha a levava como locais com marcas de prestígio social, como nas linhas 21, 22, 23 e 24 ("a gente frequentava os lugares bo:ns com ela $\downarrow$ ia no

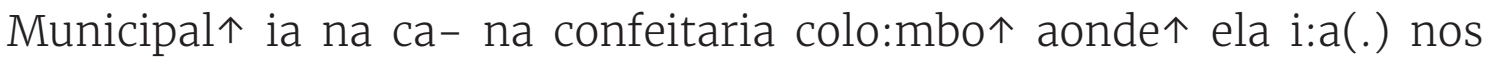
aniversários das cria:nças >nos aniversários todos a gente frequentava com ela $\downarrow<")$. A escolha do adjetivo "bom", como item avaliativo, deixa a definição precisa de exemplificação de locais aos quais uma mãe levaria suas filhas, e não empregadas domésticas, a posicionando, novamente, em papel externo ao estigma inscrito nela pela sociedade.

No Excerto 2, Lia responde ao questionamento acerca das situações de racismo que ela tenha vivido ao longo de sua vida e afirma, primeiramente, que nunca sofreu discriminação. Mais à frente, dá alguns exemplos de situações em que viu sua madrinha respondendo de forma ríspida a situações que tipificam o racismo, mas que Lia não percebe como tal. Desta forma, mais uma vez, Lia vai construindo a madrinha como benevolente e protetora.

Excerto 2 - "as pessoas tendiam a não me falar nada"

\begin{tabular}{|c|c|c|}
\hline Lia & $\begin{array}{l}25 \\
26 \\
27 \\
28\end{array}$ & 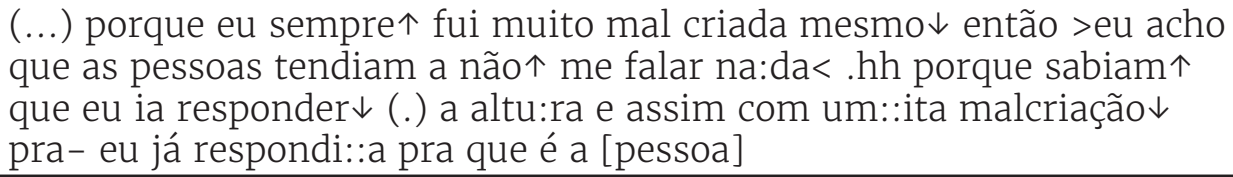 \\
\hline Pesq & $\begin{array}{l}29 \\
30\end{array}$ & outra [resposta] \\
\hline Lia & $\begin{array}{l}31 \\
32\end{array}$ & $\begin{array}{l}\text { [é pra] que ninguém me dissesse mais } \uparrow \text { nada } \downarrow \text { minha resposta } \\
\text { era de mane:ira >que a pessoa se colocasse no lugar } \uparrow \text { dela } \downarrow<\end{array}$ \\
\hline
\end{tabular}


Logo depois, como se pode observar, ela completa que nunca sofreu racismo por nunca ter deixado que ele acontecesse. Não há a percepção, ali, de que se foi necessária uma resposta "mal criada", significa que houve uma situação discriminatória anterior à resposta. A projeção de self de Lia novamente a retira da marca de estigma e do sofrimento rotineiro resultante de ações racistas por ser uma mulher negra. Como sua criação foi diferenciada, ela idealiza não possuir, portanto, experiências de situações opressoras que outras mulheres que dividem sua conjuntura passam.

Esse comportamento discursivo pode ser melhor entendido pelo fato de que em encontros mistos, como a entrevista aqui analisada, existe uma interação assimétrica que motiva o estigmatizado a comportar-se de modo agressivo, pois se encontra pronto para realizar leituras dos significados não intencionais nas ações do outro não estigmatizado (GOFFMAN, 1988, p. 27).

No Excerto 3, Lia inicia a sua história de entrada na instituição contextualizada na seção 2. Ela conta que foi alocada em um setor onde entenderam que ela seria copeira e um colega de trabalho a solicitou que servisse café e água, o que a deixou extremamente irritada. 
v. 9 (2)

61-78

maio-ago 2019

Excerto 3 - "eu não sirvo cafezinho nem lá em casa"

\begin{tabular}{|c|c|c|}
\hline Lia & $\begin{array}{l}33 \\
34 \\
35 \\
36 \\
37 \\
38 \\
39 \\
40 \\
41 \\
42 \\
43 \\
44 \\
45 \\
46 \\
47 \\
48 \\
49 \\
50 \\
51 \\
52 \\
53 \\
54 \\
55 \\
56 \\
57 \\
58 \\
59 \\
60 \\
61\end{array}$ & 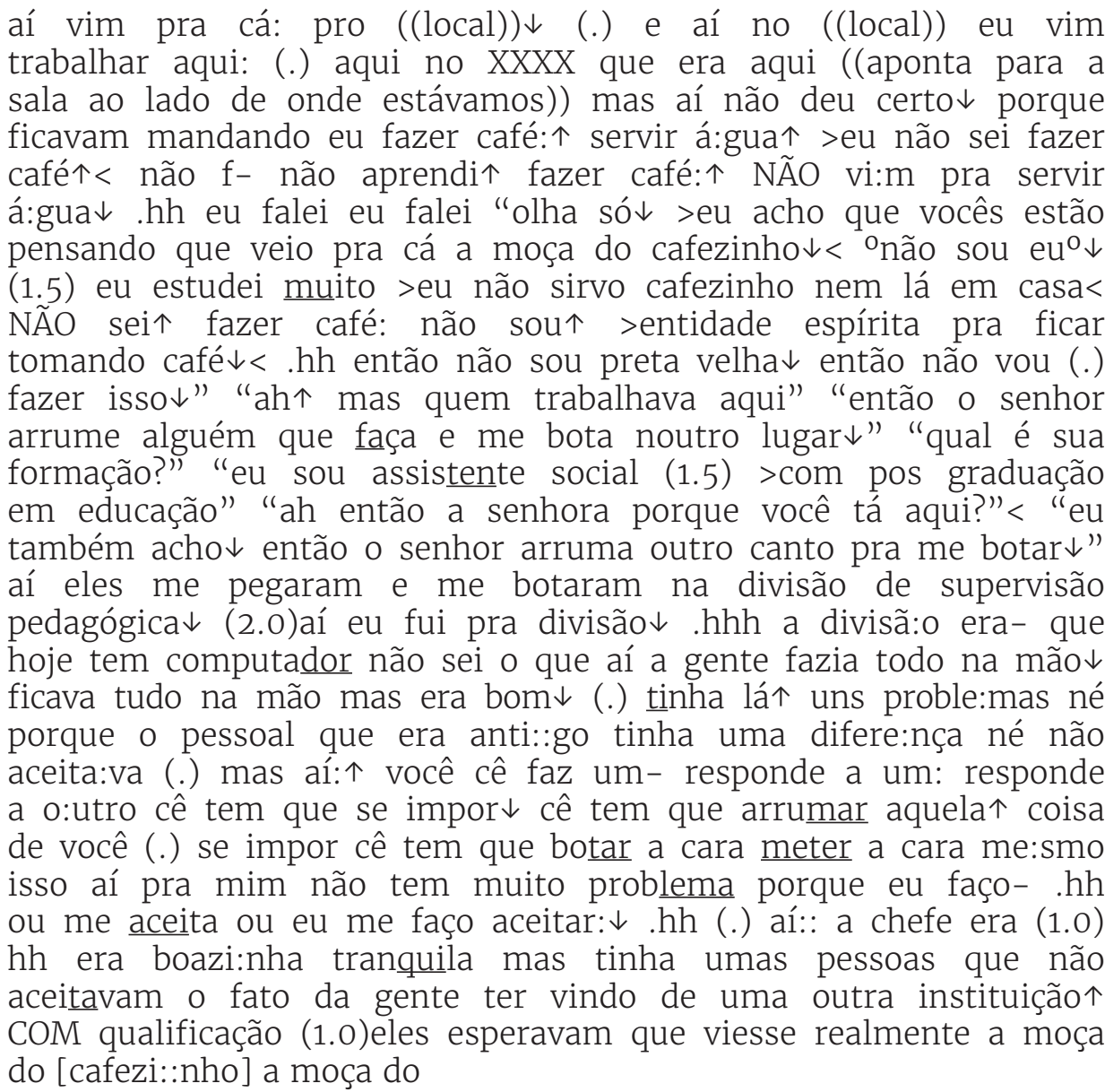 \\
\hline Pesq & 62 & [mas por que^ que eles esperavam que viesse?] \\
\hline Lia & 63 & não sei $\downarrow$ o que que falaram $\downarrow$ não sei o que que disseram pra e:les $\downarrow$ \\
\hline Pesq & 64 & >era você e mais quantas pessoas?< \\
\hline Lia & $\begin{array}{l}65 \\
66 \\
67 \\
68 \\
69 \\
70 \\
71 \\
72 \\
73 \\
74\end{array}$ & 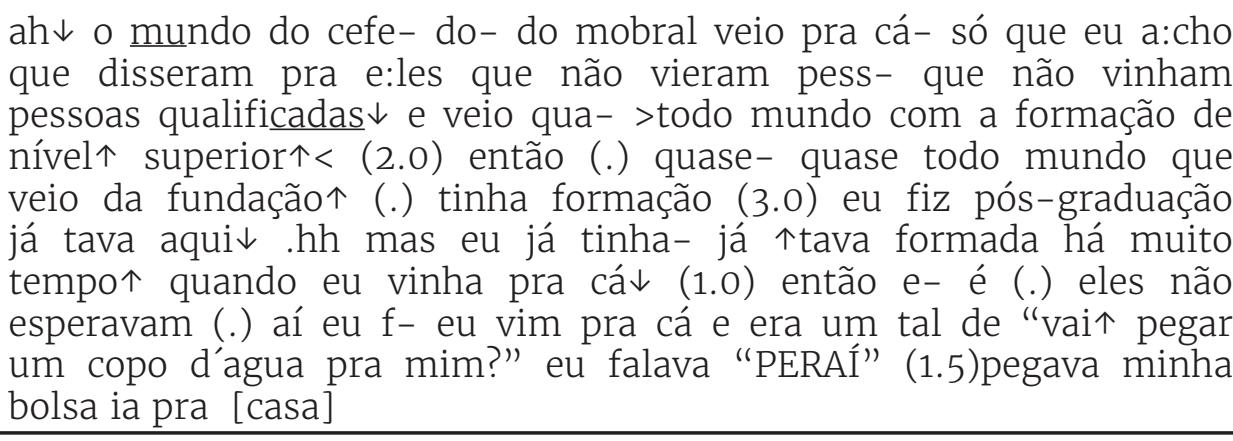 \\
\hline Pesq & 75 & [veio] mais [gente] \\
\hline Lia & 76 & [veio o [que?] \\
\hline Pesq & $\begin{array}{l}77 \\
78 \\
\end{array}$ & [pro mesmo setor que você \\
\hline Lia & 79 & [não $\downarrow$ eu vim sozinha pra cá $\downarrow$ ] \\
\hline Pesq & $\begin{array}{l}80 \\
81\end{array}$ & 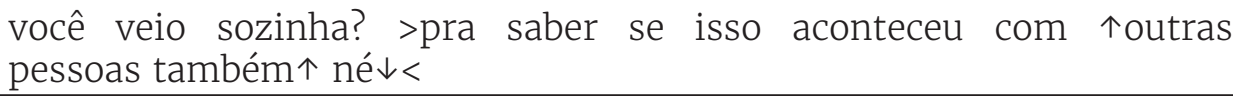 \\
\hline
\end{tabular}




\begin{tabular}{|l|l|l|l|}
\hline \multirow{4}{*}{ Lia } & 82 & não sei $\downarrow$ se aconteceu $\downarrow$ osei que comigo aconteceu isso mas como \\
& 83 & eu resolvi logo falei "olha só Rica:rdo" era um cara que tinha \\
& 84 & aqui=mas ele foi ótimo comigo $\downarrow$ (.) falei "olha só Ricardo (.) \\
& 85 & eu não gos- eu não sei fazer café:: NÃO sirvo pra serv- serv- \\
& 86 & NÂO vim pra isso $\downarrow$ NÃO gosto de fazer i:sso" & \\
\hline
\end{tabular}

Nesse momento, ela deixa explícita a sua formação em nível superior, que imediatamente a retira do lugar de servente. É importante observar que mais uma vez ela retoma a sua formação acadêmica para ratificar a sua identidade social que a afasta do lugar de mulher negra e oprimida, dando força a sua posição de não oprimida. Essa é uma situação vivida que se categoriza como racismo, mas que, ao longo de suas narrativas, Lia vem tentando negociar a inexistência.

Goffman (1988, p. 18) aborda a tentativa de "correção" do que o estigmatizado considera como base objetiva de seu defeito nos casos em que tal conserto é possível. Em sua narrativa, a força de formação acadêmico-profissional da participante é visível em seu discurso ao retomar, ordinariamente, o fato de ter chegado a altos níveis de formação. No encontro do que Goffman idealiza, Lia não busca necessariamente um status completamente "normal" em sua visão, que a retire do estereótipo da mulher negra, mas transforma seu self, de modo a apresentar "provas" de que "corrigiu" sua posição (GOFFMAN, 1988, p. 19).

Seguindo a análise, é importante deixar exposto o desconforto da pesquisadoraao perguntar seo mesmoacontecia com os demais funcionários que haviam sido transferidos com ela. O incômodo é apresentado desde a linha 62 ("[mas por quê que eles esperavam que viesse?]") quando não completou sua frase com a palavra "copeira", na linha 64 (">era você e mais quantas pessoas?") e nas linhas 80 e 81 ("você veio sozinha? >pra saber se isso aconteceu com $\uparrow$ outras pessoas também $\uparrow$ né $\downarrow<")$. De modo implícito, o que se quis perguntar, diante de toda a narrativa contada até aquele momento, era se havia alguma percepção por parte da participante de que o fato de a terem confundido com uma copeira se dava por ela ser negra, e não pelo desconhecimento de sua formação acadêmica somente, o que se constitui racismo institucional.

No mesmo caminho, Lia indica não entender o que se quer perguntar nas entrelinhas, e torna a responder nas linhas 65, 66 e 67 ("só que eu a:cho que disseram pra e:les que não vieram pess- que não vinham pessoas qualificadas $\downarrow$ ") que esta situação ocorreu pela despretensiosa falta de informação em relação à qualificação dos funcionários transferidos para tal setor. Entretanto, das linhas 83 a 86 
V. $9(2)$

61-78

maio-ago

2019

("olha só Ricardo (.) eu não gos- eu não sei fazer café:: NÃO sirvo pra serv- serv- NÃO vim pra isso $\downarrow$ NÃO gosto de fazer i:sso") ela deixa explícita a sua hesitação em utilizar a palavra "servir", preponderante função de empregada doméstica, que demonstraria, no momento da entrevista, que ela havia entendido de fato o meu questionamento. Ela não constrói a questão racial como relevante neste momento.

Lia, então, transforma a palavra "servir" em "isso", generalizando a ação e distanciando, assim, a possibilidade de demonstrar que tem consciência do problema social de estereótipo, marcado pelo racismo, que sofreu naquele momento de sua vida. Com esta reação de discurso junto à reação da pesquisadora no momento do questionamento, concordamos com Goffman (1988, p. 40) que aborda o modelo de "normalização" que trata o estigmatizado como igual a outro não estigmatizado. Isso acontece no momento em que a participante se apresenta como uma pessoa sem estigma, ainda que não esconda necessariamente a marca de seu estigma.

No Excerto 4, novamente ela remonta a ideia de que não sofreu preconceitos e que, nas poucas situações que viveu e lembra, ela não consegue perceber se ocorreram por ter sido acolhida como filha da empregada ou se porque era negra, não associando as duas categorias.

Excerto 4: "elas não são empregadas e não serão"

\begin{tabular}{|c|c|c|}
\hline Lia & $\begin{array}{l}87 \\
88 \\
89 \\
90 \\
91 \\
92 \\
93 \\
94 \\
95 \\
96 \\
97 \\
98\end{array}$ & 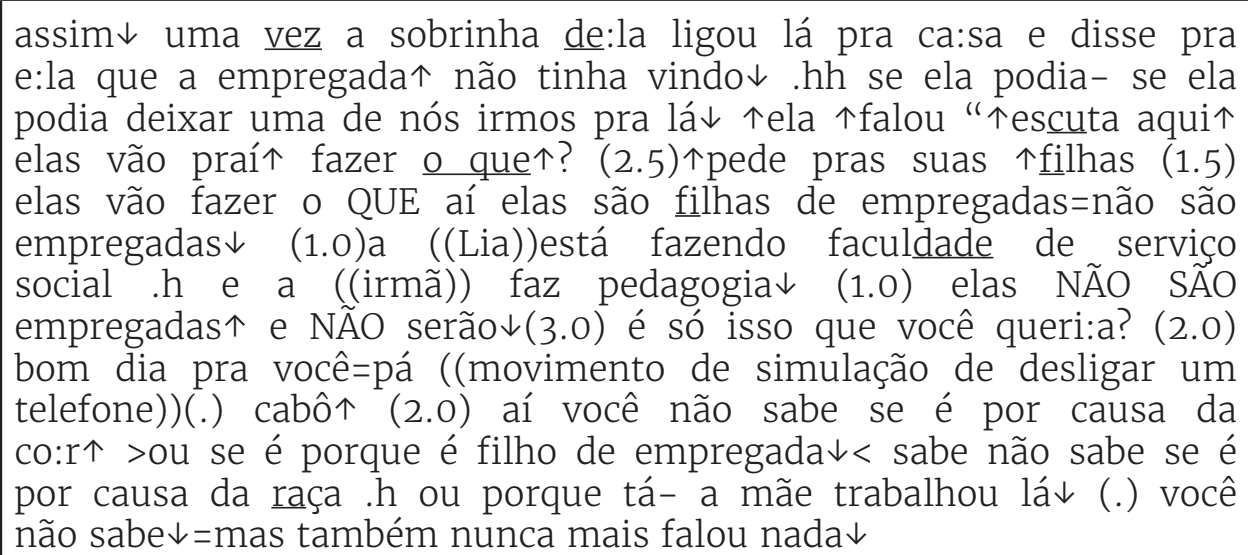 \\
\hline
\end{tabular}

As linhas 91 a 94 ("elas são filhas de empregadas=não são empregadas $\downarrow$ (1.0) a ((lia)) está fazendo faculdade de serviço social .h e a ((irmã)) faz pedagogia $\downarrow$ (1.0) elas NÃO SÃO empregadas $\uparrow$ e NÃO serão $\downarrow(3.0) "$ ) retornam ao discurso de que sua qualificação a retira do papel de empregada doméstica, desta vez de modo mais explícito, porém, em situação, segundo sua narrativa, não vivida por ela e sim por sua madrinha. 
Nas linhas 96, 97 e 98 ("você não sabe se é por causa da co:r个 $>$ ou se é porque é filho de empregada $\downarrow<$ sabe não sabe se é por causa da raça .h ou porque tá- a mãe trabalhou lá $\downarrow$ (.)") expõe a dúvida que solidifica a sua formação identitária, tendo em vista não saber ao certo se faz parte do grupo de pessoas com as atribuições determinadas para o estigma que uma mulher negra possui. Em diálogo com Goffman (1988, p. 20), o estigmatizado "pode romper com aquilo que é chamado de realidade, e tentar obstinadamente empregar uma interpretação não convencional do caráter de sua identidade social", completando a ideia do paradoxo que a participante parece experimentar sem perceber.

No excerto 5, novamente ela afirma a postura dela frente às situações que teve que enfrentar, ratificando a suposta força de resposta que relata sempre ter possuído.

Excerto 5: "tem que se defender"

\begin{tabular}{|c|c|c|}
\hline Lia & $\begin{array}{l}100 \\
101 \\
102 \\
103 \\
104 \\
105 \\
106 \\
107 \\
108 \\
109 \\
110 \\
111 \\
112 \\
113 \\
114 \\
115 \\
116\end{array}$ & 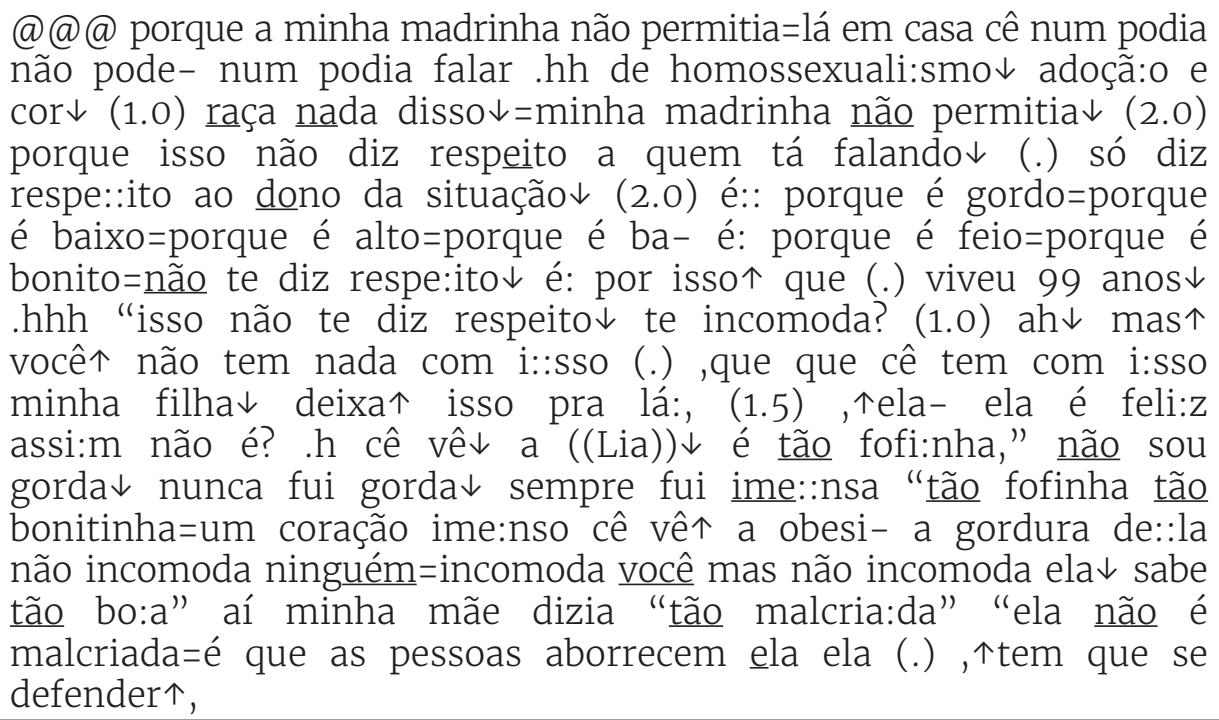 \\
\hline
\end{tabular}

Ao falar sobre as características de sua madrinha, que a ratificam como uma "pessoa de bom coração", Lia não somente justifica o fato de ter sido acolhida na casa da patroa de sua mãe como filha, construindo novamente sua madrinha como benevolente, como mostra a sua formação ideológica familiar. Essa formação ideológica aparece ao contar que foi criada em uma casa onde não se falava sobre as diversidades, conforme relata das linhas 100 a 104 ("porque a minha madrinha não permitia=lá em casa cê num podia não podenum podia falar .hh de homossexuali:smo $\downarrow$ adoçã:o e cor $\downarrow$ (1.0) raça

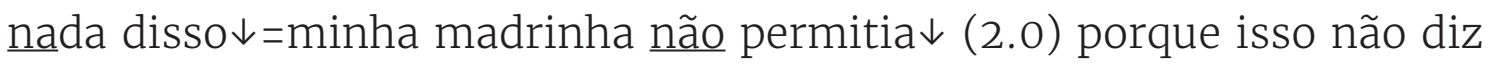
respeito a quem tá falando $\downarrow$ (.) só diz respe::ito ao dono da situação $\downarrow$ $\left.(2.0)^{\prime \prime}\right)$. 
V. 9 (2)

61-78 maio-ago 2019

Goffman (1988, p. 42) entende a força da formação de uma experiência moral embutida na vida do indivíduo estigmatizado protegido por seu círculo doméstico como grande fator responsável por momentos críticos de aprendizagem do estigma quando ele passa a frequentar ambientes mistos sozinho. Assumindo que a diferenciação por cor e gênero não existem, mesmo que por uma intenção específica de sua madrinha de uma postura não invasiva sobre outras pessoas, a madrinha impossibilita a problematização das questões sobre diversidade e simultaneamente distancia Lia da realidade do estigma que viveria.

Não coube aqui realizar uma análise com juízo de valor sobre a postura que sua madrinha tomou, mas mostrar a importância da escolha de Lia por ter contado esta narrativa para compor sua história de vida, que é entendida aqui como um dos fatores determinantes para seu constante trabalho de face, frente ao estigma que possui. Cabe lembrar que Goffman (1988, p. 54) aponta a existência dos signos que tendem a uma quebra da imagem negativa do estigmatizado. De modo a levar a uma direção positiva de imagem desejada, Lia trouxe em seu discurso a constante lembrança de que era uma pessoa bem formada, provocando dúvidas acerca da validade da identidade social virtual projetada aos negros, a qual abordei no início desta análise. Para tal, Lia lança mão do que Goffman chama de desidentificadores que, em seu caso, é a sua alta formação acadêmica, transmitindo a informação social desejada.

\section{Considerações finais}

Através de características historicamente estabelecidas para a população negra, o estigma da cor da pele foi constituído como marca de comportamentos e histórias de subordinação. No caso da participante deste estudo, durante a interação emergiu o esforço para projeção de um self guiado no sentido oposto ao esperado pelo estigma que a acompanha. Isso aparece não só pela história de vida que narrou ao longo da entrevista, mas também nos comportamentos durante este momento interacional. As análises de marcadores de discurso como repetições, silêncios e entonações demonstraram a reconstrução identitária que naquele momento estava se remodelando.

A participante possui clareza do que é esperado de uma mulher negra em uma sociedade opressora e desde o início da narrativa que remonta sua história de vida ela procura transgredir o destino inexorável ao qual seu estigma a apresentaria. Na interação mista 
através da entrevista proposta, percebeu-se um esforço conjunto para a "normalização" da situação interacional. Do mesmo modo, ficou explícito o empenho da participante estigmatizada em parecer "igual" e o cuidado da pesquisadora em tratá-la como se ali houvesse a ausência da marca estigmatizadora e sua relação direta com a composição de sua história de vida.

Percebe-se, então, um controle pericioso da imagem projetada que a participante tem de si, diante de um self estigmatizado, com o objetivo final de aceitação social. Por isso, busca em suas narrativas mostrar-se sob uma luz favorável, de modo que não só na interação vivida no momento da entrevista sua imagem seja aceita, mas também deixando perceptível em suas histórias que sua aceitação social foi exitosa, ao negar as situações de racismo. Por fim, engajou-se na desconstrução dos signos estigmatizantes, ressignificando as marcas "inexoráveis" do destino de uma mulher negra em uma sociedade de normativas estabelecidas por brancos. Isso pode ser visto através da quebra de expectativas ao se construir como uma pessoa com sucesso profissional e pessoal em sua vida.

\section{Convenção de transcrição}

Tabela 1 - Convenção de Transcrição

\begin{tabular}{|l|l|}
\hline$[$ texto $]$ & Falas sobrepostas \\
\hline$=$ & Fala colada \\
\hline$(1.8)$ & Pausa \\
\hline$()$. & Micropausa \\
\hline, & Entonação Contínua \\
\hline$\cdot$ & Entonação Ponto Final \\
\hline$?$ & Entonação de Pergunta \\
\hline- & Interrupção abrupta da fala \\
\hline$:$ & Alongamento de som \\
\hline$>$ texto $<$ & Fala mais rápida \\
\hline$<$ texto $>$ & Fala mais lenta \\
\hline${ }^{\circ}$ texto ${ }^{\circ}$ & Fala com volume mais baixo \\
\hline TEXTO & Fala com volume mais alto \\
\hline texto & Sílaba, palavra ou som acentuado \\
\hline$($ texto $)$ & Dúvidas \\
\hline XXXX & Texto inaudível \\
\hline$(($ texto) $)$ & Comentários da transcritora \\
\hline
\end{tabular}


V. 9 (2)

61-78

maio-ago

2019

\begin{tabular}{|l|l|}
\hline$@ @ @$ & Risada \\
\hline$\downarrow$ & Entonação descentente \\
\hline$\uparrow$ & Entonação Ascendente \\
\hline Hhh & Expiração audível \\
\hline .hhh & Inspiração audível \\
\hline Fonte· SCHNACK, PISONI \& OSTERMANN (2005).
\end{tabular}

\section{Referências}

Biar, L. de A. Desvio e estigma: caminhos para uma análise discursiva. In: Calisdoscópio, São Leopoldo, v. 13, n. 1, p. 113-121, jan./abr. 2015.

FABRICIO, B. F.; BASTOS, L. C. Identidade de grupo: a memória como garantia do nós face ao outro. In: PEREIRA, M. G. D.; BASTOS, C. R. P.; PEREIRA, T. C. (Orgs.). Discursos sócio-culturais em interação: Interfaces entre a narrativa, a conversação e a argumentação: navegando nos contextos da escola, saúde, empresa, mídia, política, gênero e migração. Rio de Janeiro: Garamond, 2009. p. 39-66.

FREYRE, G. Casa-Grande \& Senzala: formação da família brasileira sob o regime da família patriarcal. 51a. ed. rev. São Paulo: Global Editora, 2006.

GOFFMAN, E. Estigma: notas sobre a manipulação da identidade deteriorada. Tradução de Márcia Bandeira de Mello Leite Nunes. 4a. ed. Rio de Janeiro: Livros Técnicos e Científicos, 1988.

A representação do eu na vida cotidiana. Petrópolis: Vozes, 2009.

A situação negligenciada. In: RIBEIRO, B. T.; GARCEZ, P. (Orgs.). Sociolinguística Interacional. São Paulo: Loyola, 2002.

LABOV, W. "The Transformation of Experience in Narrative Syntax". In: _. Language in the Inner City. Philadelphia: University of Pennsylvania Press, 1972.

LINDE, C. Life Stories: The Creation of Coherence. New York: Oxford University Press, 1993.

RABELO, A. O. A importância da investigação narrativa na educação. Educ. Soc., Campinas, V. 32, n. 114, p. 171-188, jan./mar. 2011.

MOITA LOPES, L. P. da. Socioconstrucionismo: discurso e identidade sociais. Campinas: Mercado de Letras, 2003.

SCHNACK, C.; PISONI, T.; OSTERMANN, A. Transcrição de fala: do evento real à representação escrita. Entrelinhas, São Leopoldo, v. 2, n. 2, 2005. 